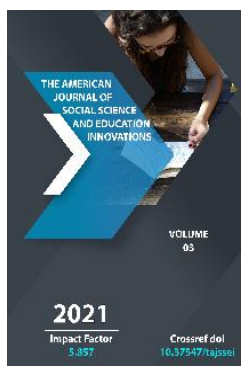

\title{
Improving The Effectiveness Of Writing Development Of Medical Students In The Russian Language Classes
}

\author{
U. E. Akhmedova \\ Senior Teacher Of Fergana Medical Institute Of Public Health, Uzbekistan
}

Journal Website:

http://theamericanjour

nals.com/index.php/taj

ssei

Copyright: Original content from this work may be used under the terms of the creative commons attributes 4.0 licence.

\section{ABSTRACT}

This article provides information that medical students in the process of learning mastered several foreign languages, especially one of the greatest languages - Russian. Students of medical universities should pay special attention not only to oral speech, but also to the development of written speech. Their professional activities are reflected in writing, so they must write competently, perform various types of written work that activate mental activity and increase the literacy of medical students.

\section{KEYWORDS}

Cultural figures, qualified specialist, universal moral values, linguistic and methodological analysis, specifics of the studied vocabulary, orthograms, syntactic constructions, moral and moral qualities.

\section{INTRODUCTION}

In the territory of the Republic of Uzbekistan, Language", the state language is Uzbek. The according to the Law "On the State

$$
\text { Uzbek }
$$


language occupies a dominant position in office work and the mass media. But history has so ordered that in our country the Russian language has become the language of interethnic communication, its knowledge opens the way to mutual understanding between people of all nationalities living in our Republic.

As you know, since ancient times, in the East, cultural and scientific figures, in addition to their native language, spoke Arabic and Persian. This was not an end in itself, but a means of mastering the universal culture.

"A new generation, educated, free from all remnants of the past, young people are now becoming the decisive driving force of democratization, liberalization, renewal and confident progress of the country. The preparation of an educated and intellectually developed generation is an urgent task of the entire education system, " the First President of the country, I. A. Karimov, noted in his speech at the International Conference on Education[1].

The relevance of the research is that in the course of learning, students master several languages, English, German, French, and especially one of the greatest languages Russian. The Russian language will expand the circle of communication, help you become a qualified specialist, get deep knowledge, good theoretical training in your chosen specialty. Knowledge of the Russian language opens up access to world scientific values, expands the scope of professional activity. If the attention to the study of the Russian language is weakened, the spiritual culture of the younger generation will be impoverished, and the opportunities to deeply master both professional and universal knowledge, which contain high moral values, will be lost.

\section{MATERIAL AND METHODS}

Russian Russian has been reduced in the number of hours devoted to the Russian language, and there is a growing need to organize the educational process in such a way that interest in the Russian language does not fall, but increases. Currently, students of local nationality who study at a medical university face difficulties:

1. Overcoming the complexity of the special offer itself

2. Poor knowledge of the Russian language.

Teaching is conducted mainly in the Uzbek language, but to enter the educational and professional sphere of communication, to master the future profession.

The aim of the work is that in teaching Russian to students of national groups, special attention should be paid not only to oral speech, but also to the development of written speech of students. They should correctly reflect their professional activities on the letter. Therefore, the teacher of the Russian language in the course of his work should pay attention to written speech, which activates mental activity and increases the literacy of medical students. In this process, an important role is played by the written work chosen by the teacher, in particular, dictation and presentation. Students are taught to understand what they read, observe language facts, establish logical connections, select the main thing, make generalizations and conclusions, and correctly express their thoughts in writing.

\section{DISCUSSION AND CONCLUSION}

Based on the tasks set, the following materials and research methods were selected and applied:

- Analysis of scientific and methodological literature on medical topics; 
- A comprehensive research method that allows you to identify the specifics of the studied lexical group, including familiarization with the ways of interpreting medical terms in different dictionary sources;

- Linguistic and methodological analysis of educational and scientific texts in the specialty of university students and relevant training materials. Dictation, as you know, is a type of written work in which the material intended for recording is pre - listened to by students in its entirety, then written down in parts under dictation-verbatim or with changes due to the teacher's task. You can conduct a training dictation. It is used at the first stage of fixing the topic. It is carried out on the material of a dictionary, phrases, sentences, or at the level of a coherent text.

The dictation material may consist of individual words, phrases, sentences, or a coherent text. You can conduct a training dictation. It is applied at the first stage of fixing. It is carried out on the material of a dictionary, phrases, or proposals, or at the level of a coherent text. For example, the teacher decided to check how the students learned the spelling of medical terms. Teaching dictation at the sentence level requires more sustained attention and tension from students.

Selective dictation is carried out at the stage of fixing the studied topic. The teacher reads individual sentences, inviting the group to write out words or phrases with the questions asked.

Distribution dictation is carried out after studying a section of grammar in order to consolidate the material. Students write words under dictation and their spelling is checked on a video projector.
The commented dictation is usually based on the material of phrases or short sentences, i.e. students must remember and repeat. Students write words under dictation, only the studied orthograms are commented on.

Dictation by analogy is recommended when fixing the studied part of speech, for example, a verb or an adjective, a pronoun, etc. The teacher introduces the group to the content of the text, then explains the task. For example: replace past verbs with present verbs, form adjectives from nouns.

Creative dictation is a type of exercise in which students insert words of a certain grammatical category into the dictated text or replace some words with others on the instructions of the teacher. For example: creative dictation to expand the text. At the request of the teacher, students can expand the text by inserting prepositions, conjunctions, generalizing words, etc.

Free dictation is a transition from dictation to presentation: the teacher dictates the text in parts, and the students do not verbatim, but freely reproduce it. It is an excellent tool for preparing students to master the skills necessary for the presentation of a whole text, it helps to overcome the main drawback of the students ' presentations.

The control dictation is conducted in order to check how students have learned what they have learned, how they have learned to use the learned rules in writing. The texts of the DLC control dictation should be saturated with the studied forms or syntactic constructions.

Presentations can be educational and control. They should also be used as homework. The teacher, in accordance with the specific conditions and characteristics of the group, as well as with the target orientation of the lesson, can change both the method of 
conducting written work and the nature of the written work itself.

Practical work and research have allowed us to outline three areas in the organization of professional training of medical students in the process of learning the Russian language:

1. Familiarization of students with the problems and vocabulary of texts with moral content, with tasks and exercises for mastering the specified vocabulary.

2. Determining the capabilities of textbooks and textbooks on the Russian language for medical schools.

3. Development of classes that allow for the simultaneous solution of training and educational tasks, as well as exercises for the assimilation of medical terminology, as well as used in the formation of moral qualities.

The first set of exercises involves the formation of skills of perception and use of words with the semantics of morality in speech. These exercises perform two functions: they provide the perception and comprehension of words of moral meaning and contribute to their introduction into the active speech of students.

The exercises of this complex are characterized by tasks such as: choose lexical synonyms for words with a moral meaning; answer questions, make phrases and sentences, etc. For example: answer questions using words of moral meaning: What qualities should a doctor have?

What character traits are necessary for a modern doctor?

How should a doctor treat people?

The following set of exercises is aimed at developing the skill of using such vocabulary in speech in various combinations. Some exercises contribute to the formation of skills and abilities in the use of words, phrases, sentences containing educational meaning at the level of microtext. The exercises include creative tasks: the use of words, phrases, sentences, and $\mathrm{CCC}$ in the text with moral content. Each of these complexes is used in certain types of classes, chosen depending on the educational tasks. It is possible to illustrate the use of some exercises by the example of one of the types of classes united by a common professionally - oriented task within the framework of a lexical topic. For example: "The heroic act of a doctor during the COVID-19 pandemic", with which students work in class, then state the content of the text, highlighting information about the character traits of doctors fighting for people's lives. During the discussion of the content of the text, it is emphasized that high moral qualities help people to overcome difficulties, be patient and achieve goals.

The basis of tasks aimed at mastering the lexical and syntactic compatibility of words of moral and moral meaning and developing the skills of using them in speech are exercises such as:

1. Match the verbs to the words of moral meaning. Explain the meaning of the received phrases: bravery, heroism, honor, perseverance, truthfulness, duty, kindness, humanity, etc.

2. Verbs for reference: show, provide, recognize, seek, expect, demand, etc.

3. Exclude from the list those words that cannot be combined with the above words of moral meaning:

Courageous ( act, character, friend, doctor, friend);

Perseverance ( to protect, to show, to strive, to demand); 
Boldly ( to keep silent, to say, to persuade, to speak).

Given the small volume of the text and the work on the semantics of words denoting educational concepts, you can use the text to develop the skill of introductory reading. The task of such reading: as much as possible to assimilate the content of the text. Verification of the assimilation of the content of the text is carried out using questions such as:

1. In what cases should you show bravery and courage?

2. How is the character of a doctor brought up?

3. What can be said about doctors who have chosen a difficult and noble path?

4. When is it necessary to be bold and truthful, not to give up in the face of difficulties, to stand up for the weak, to stand up for the truth?

\section{ACKNOWLEDGEMENT}

Experience has shown that various types of written work carried out when consolidating, repeating the material being studied, and in order to test the assimilation of knowledge, arouse students ' interest in the Russian language, activate their mental activity, develop not only oral speech, but also written, increase the literacy of medical students, fix the rules of spelling.

\section{REFERENCES}

1. Karimov I. A. The path we have chosen is the path of democratic development and cooperation with the progressive world. Tashkent: Uzbekistan, 2003.

2. Panova E. V. Work with text in educational institutions. - Samara, 2011.
3. Davshan O. P. Working with text material at the university. - Saint-Petersburg, 2010.

4. Baranov M. T. Studying terminological vocabulary/ / Teaching the Russian language. - Moscow, 1981.

5. Budakov R. A. Man and his language. Moscow, 1994. 